\title{
Restoration of normal glucose tolerance in severely obese patients after bilio-pancreatic diversion: role of insulin sensitivity and beta cell function
}

\author{
A. Mari • M. Manco • C. Guidone • G. Nanni • \\ M. Castagneto $\cdot$ G. Mingrone $\cdot$ E. Ferrannini
}

Received: 13 February 2006 / Accepted: 2 May 2006 / Published online: 4 July 2006

(C) Springer-Verlag 2006

\begin{abstract}
Aims/hypothesis The aim of this study was to analyse the mechanisms underlying the improvement in glucose tolerance seen in morbidly obese patients undergoing biliopancreatic diversion (BPD).

Subjects and methods We evaluated glucose tolerance (by OGTT), insulin sensitivity (euglycaemic-hyperinsulinaemic clamp and the OGTT index OGIS) and beta cell function (OGTT modelling analysis) in 32 morbidly obese (BMI=52 $7 \mathrm{~kg} / \mathrm{m}^{2}$, mean \pm SD) patients (12 with NGT, 9 with IGT and 11 with type 2 diabetes), before and after BPD, and in 22 lean control subjects. Patients were studied before and from 7 days to 60 months after surgery.

Results BPD improved glucose tolerance in all subjects, who after surgery all had normal glucose tolerance. Insulin sensitivity was restored to normal levels in all subjects (preBPD $341 \pm 79 \mathrm{ml} \mathrm{min}^{-1} \mathrm{~m}^{-2}$, post-BPD $511 \pm 57 \mathrm{ml} \mathrm{min}^{-1} \mathrm{~m}^{-2}$, lean $478 \pm 49 \mathrm{ml} \mathrm{min}^{-1} \mathrm{~m}^{-2}$ ). The insulin sensitivity change was detectable within 10 days of BPD. At baseline, beta cell sensitivity to glucose was impaired in diabetic subjects $(25$
\end{abstract}

A. Mari $(\bowtie)$

CNR Institute of Biomedical Engineering,

Corso Stati Uniti 4,

35127 Padua, Italy

e-mail: andrea.mari@isib.cnr.it

M. Manco $\cdot$ C. Guidone $\cdot$ G. Mingrone

Department of Internal Medicine, Catholic University 'S. Cuore',

Rome, Italy

G. Nanni $\cdot$ M. Castagneto

Department of Surgery, Catholic University 'S. Cuore',

Rome, Italy

E. Ferrannini

Department of Internal Medicine,

University of Pisa School of Medicine,

Pisa, Italy
[18] $\mathrm{pmol} \mathrm{min}^{-1} \mathrm{~m}^{-2} 1 \mathrm{mmol}^{-1}$, median [interquartile range]) compared with lean subjects ( 82 [98]; $p \leq 0.05)$. After BPD, beta cell glucose sensitivity showed a tendency towards improvement but remained impaired in diabetic subjects (30 [62]; $p<0.01$ vs lean). Total insulin output decreased in parallel with the insulin sensitivity increase in all groups. In the whole patient group, mean OGTT glucose levels were inversely related to both insulin sensitivity and beta cell glucose sensitivity $\left(r^{2}=0.67\right.$, partial $r=-0.76$ and -0.41 , respectively). NEFAs, leptin and adiponectin were related to insulin sensitivity but could not explain the early improvement.

Conclusions/interpretation Following BPD, glucose tolerance was restored mainly as a result of a rapid and large improvement in insulin sensitivity.

Keywords Bariatric surgery - Beta cell function .

Bilio-pancreatic diversion - Glucose tolerance .

Insulin resistance - Insulin secretion - Insulin sensitivity ·

Morbid obesity · Type 2 diabetes

\section{Abbreviations \\ BPD bilio-pancreatic diversion \\ OGIS oral glucose insulin sensitivity}

\section{Introduction}

Recent experience with bariatric surgery for severe obesity has shown that this form of treatment can restore normal glucose tolerance in the majority of diabetic subjects [1]. Two surgical procedures, bilio-pancreatic diversion (BPD) and Roux-en-Y gastric bypass, have proven so effective in restoring normoglycaemia that they have been proposed as potential therapies for diabetes $[2,3]$. 
In morbidly obese patients undergoing bariatric surgery, one factor contributing to the restoration of normal glucose tolerance is the surgery-induced increase in insulin sensitivity [4-7]. Although some data are available [5, 7-9], the role of beta cell function, its relationship with insulin sensitivity, and the contribution of either factor to the improvement in glucose tolerance are not clearly established. Furthermore, while there is evidence that the improvement in circulating glucose levels occurs in days [10], it is not clear how early after surgery the improvement in insulin sensitivity occurs.

In this study, we used an OGTT and validated insulin sensitivity and beta cell function methods in severely obese subjects, covering a wide spectrum of glucose tolerance, who underwent BPD to elucidate the role of insulin sensitivity, beta cell function, and their interplay in the restoration of glucose tolerance.

\section{Subjects and methods}

\section{Subjects}

We studied 32 morbidly obese subjects undergoing BPD. Before surgery, 12 patients had NGT, 9 had IGT and 11 had overt type 2 diabetes. Patients were restudied at a variable time after surgery (a median of 1,220 days for NGT, 244 days for IGT and 153 days for type 2 diabetes). Normal reference values for insulin sensitivity and beta cell function were obtained from a group of 22 lean, non-diabetic subjects. The clinical and metabolic characteristics of the study subjects are shown in Table 1 . An additional group of 25 severely obese patients (13 men and 12 women; 16 NGT, 1 IGT, 8 type 2 diabetes; age $42 \pm 10$ years [mean \pm SD]; BMI $44 \pm 6 \mathrm{~kg} / \mathrm{m}^{2}$ ) undergoing abdominal surgery for reasons other than BPD (mainly cholecystectomy and abdominal hernia) was included to test if surgical intervention itself affected insulin sensitivity and glucose tolerance. In these subjects, an OGTT was performed before surgery and within 10 days of surgery. All patients received the same parenteral nutrition regimen $(\sim 7,100 \mathrm{~kJ} /$ day) during the first 6 days after surgery. The nature and purpose of the investigation were explained to all subjects before they agreed to participate in the study, which complied with the guidelines of the ethics committee of the hospital.

\section{BPD}

This malabsorptive surgical procedure [11] consists of an approximately $60 \%$ distal gastric resection with stapled closure of the duodenal stump. The residual volume of the stomach is about $300 \mathrm{ml}$. The small bowel is transected at $2.5 \mathrm{~m}$ from the ileo-caecal valve, and its distal end is anastomosed to the remaining stomach. The proximal end of the ileum, comprising the remaining small bowel (involved in carrying bilio-pancreatic juice but excluded from food transit), is anastomosed in an end-to-side fashion to the bowel, $50 \mathrm{~cm}$ proximal to the ileo-caecal valve. Consequently, the total length of absorbing bowel is reduced to $250 \mathrm{~cm}$, the final $50 \mathrm{~cm}$ of which, the so-called common channel, represents the site where ingested food and bilio-pancreatic juices mix.

\section{Body composition}

Body weight was measured to the nearest $0.1 \mathrm{~kg}$ with a beam scale, and height to the nearest $0.5 \mathrm{~cm}$ using a stadiometer (Holtain, Crosswell, UK). Lean body mass, in $\mathrm{kg}$, was calculated from total body water, determined by tritiated water injection [12]. Fat mass was then calculated as the difference between body weight and lean body mass. When determined very early (up to 1 month) after surgery, body composition was measured by electrical bioimpedance (Dietosystem, Milan, Italy).

\section{OGTT}

A standard 75-g OGTT was performed in each patient at baseline and after surgery, with blood sampling at $0,30,60$, 90,120 and $180 \mathrm{~min}$. In some tests (seven of the 64 tests in BPD subjects and 13 of the 22 tests in lean subjects), sampling was stopped at $2 \mathrm{~h}$.

Euglycaemic--hyperinsulinaemic clamp

Peripheral insulin sensitivity was evaluated by the euglycaemic-hyperinsulinaemic technique [13] in a subset of the BPD patients (26 pre-BPD and 18 post-BPD determinations). After inserting a cannula in a dorsal hand vein for sampling arterialised venous blood, and another in the antecubital fossa of the contralateral arm for infusions, the subjects rested in the supine position for at least $1 \mathrm{~h}$. They were placed with one hand warmed in a heated air box set at $60^{\circ} \mathrm{C}$ to obtain arterialised blood samples. Insulin sensitivity, as the total insulin-mediated glucose uptake ( $M$ value, in micromole per minute per kilogram lean body mass), was determined during a primed constant infusion of insulin of $240 \mathrm{pmol} \mathrm{min}^{-1} \mathrm{~m}^{-2}$. The $M$ value was calculated during the last 40-min period of the clamp.

Insulin sensitivity and beta cell function

Insulin sensitivity was calculated from the OGTT as the oral glucose insulin sensitivity index (OGIS) [14], using the $2-\mathrm{h}$ OGIS equation. This method provides an insulin sensitivity index that is an estimate of the glucose clearance during a euglycaemic-hyperglycaemic clamp, expressed in 
Table 1 Anthropometric and metabolic characteristics

\begin{tabular}{|c|c|c|c|c|c|c|c|c|}
\hline & \multirow{2}{*}{$\begin{array}{l}\text { Control } \\
\text { subjects }\end{array}$} & \multicolumn{2}{|l|}{ NGT } & \multicolumn{2}{|l|}{ IGT } & \multicolumn{2}{|c|}{ Type 2 diabetes } & \multirow{2}{*}{$\begin{array}{l}\mathrm{BPD}^{\mathrm{a}} \\
\text { effect }\end{array}$} \\
\hline & & Pre-surgery & Post-surgery & Pre-surgery & Post-surgery & Pre-surgery & Post-surgery & \\
\hline$n$ & 22 & 12 & & 9 & & 11 & & \\
\hline Sex (male/female) & $8 / 14$ & $3 / 9$ & & $4 / 5$ & & $3 / 8$ & & \\
\hline Age (years) ${ }^{\mathrm{b}}$ & $39 \pm 9$ & $35 \pm 10$ & & $43 \pm 6$ & & $47 \pm 6^{\mathrm{c}}$ & & \\
\hline Weight (kg) & $65 \pm 9$ & $139 \pm 13^{c}$ & $82 \pm 27^{\mathrm{c}}$ & $147 \pm 33^{c}$ & $116 \pm 30^{\mathrm{c}, \mathrm{d}}$ & $139 \pm 23^{c}$ & $105 \pm 17^{\mathrm{c}, \mathrm{d}}$ & + \\
\hline BMI $\left(\mathrm{kg} / \mathrm{m}^{2}\right)$ & $22.6 \pm 1.6$ & $50.0 \pm 5.3^{\mathrm{c}}$ & $29.3 \pm 8.5^{\mathrm{c}}$ & $53.7 \pm 10.3^{\mathrm{c}}$ & $42.8 \pm 10.4^{\mathrm{c}, \mathrm{d}}$ & $52.1 \pm 6.5^{\mathrm{c}}$ & $39.7 \pm 7.3^{\mathrm{c}, \mathrm{d}}$ & + \\
\hline $\begin{array}{l}\text { Mean glucose } \\
(\mathrm{mmol} / \mathrm{l})\end{array}$ & $6.3 \pm 1.0$ & $7.0 \pm 0.5^{\mathrm{c}}$ & $5.7 \pm 0.6$ & $8.6 \pm 0.9^{\mathrm{c}, \mathrm{d}}$ & $5.5 \pm 0.6^{\mathrm{c}}$ & $12.4 \pm 2.8^{\mathrm{c}, \mathrm{d}}$ & $6.3 \pm 0.8$ & + \\
\hline $\begin{array}{l}\text { Fasting insulin } \\
(\mathrm{pmol} / \mathrm{l})\end{array}$ & $38(32)$ & $114(68)^{\mathrm{c}}$ & $42(21)$ & $108(101)^{\mathrm{c}}$ & $43(29)$ & $106(56)^{\mathrm{c}}$ & $42(22)$ & + \\
\hline
\end{tabular}

Data are means \pm SD or medians (interquartile range)

${ }^{a}$ The plus sign indicates $p \leq 0.05$ for the difference between pre- and post-surgery by two-way ANOVA for repeated measures

${ }^{\mathrm{b}}$ Age at test pre-BPD

${ }^{c} p \leq 0.05$ vs control subjects by Bonferroni-Dunn test

d $p \leq 0.05$ vs the NGT group by Bonferroni-Dunn test

millilitre per minute per square metre of body surface area. In the subset of subjects in whom the clamp was also performed (44 tests), there was a strong correlation between the $M$ value and OGIS $(r=0.92, p<0.0001)$. A good correlation was also observed between the changes in OGIS and the $M$ value occurring after BPD ( $r=0.68$, $p<0.005, n=17)$. Because the $M$ value was not available in all subjects, we used OGIS to quantify insulin sensitivity in all subjects. Values obtained using this method show good correlation with those obtained by the clamp.

Beta cell function was assessed using a model describing the relationship between insulin secretion and glucose concentration, which has previously been explained in detail $[15,16]$. The model expresses insulin secretion as a sum of two components. The first component represents the dependence of insulin secretion on absolute glucose concentration at any time point, and is characterised by a dose-response function relating the two variables. The dose-response is the mean slope within the observed glucose range, denoted as beta cell glucose sensitivity. The dose-response is modulated by a potentiation factor, which accounts for several potentiating factors (prolonged exposure to hyperglycaemia, non-glucose substrates, gastrointestinal hormones, neurotransmitters). The potentiation factor is set to be a positive function of time and to average one during the experiment. It thus expresses a relative potentiation of the secretory response to glucose. In previous experiments [16, 17], we have found that insulin secretion at the end of an OGTT or meal is relatively higher than at the beginning for comparable glucose levels (i.e. when glucose returns to the basal level, insulin secretion remains higher). Potentiation thus increases during the test; this increase has been quantified as the ratio between the potentiation factor value at $2 \mathrm{~h}$ after the
OGTT and that at time zero [16, 17]. The second insulin secretion component represents a dynamic dependence of insulin secretion on the rate of change of glucose concentration. This component is termed derivative component, and is determined by a single parameter, denoted as rate sensitivity. Rate sensitivity is related to early insulin release [16, 17].

The model parameters were estimated from glucose and C-peptide concentration by regularised least-squares, as previously described $[15,16]$. Regularisation involves the choice of smoothing factors selected to obtain glucose and C-peptide model residuals with standard deviations close to the expected measurement error $(\sim 1 \%$ for glucose and $\sim 4 \%$ for C-peptide).

Basal and total insulin secretion during the OGTT were calculated from the estimated model parameters. Total insulin secretion was calculated as the integral of insulin secretion during the first $2 \mathrm{~h}$ of the OGTT, both in the 2- and 3-h OGTT protocols. Insulin secretion was expressed in picomole per'minute per'square metre of body surface area.

Statistical analysis

Data are presented as means $\pm \mathrm{SD}$, unless otherwise stated. Insulin parameters, which, in general, are not normally distributed, are presented as medians (interquartile range). ANOVA was used to compare group values, with post hoc group comparisons tested by the Bonferroni-Dunn test. Treatment-induced changes in the obese group were tested by two-way ANOVA for repeated measures. Simple and multiple regression was carried out by standard techniques, using logarithmic transformation of non-normally distributed variables. A $p$ value of $\leq 0.05$ was considered statistically significant. 


\section{Results}

Weight and glucose tolerance

At baseline, compared with lean control subjects, obese patients had higher mean plasma glucose concentrations during the OGTT, the differences being larger in IGT and type 2 diabetic subjects (Table 1). After surgery, body weight and BMI were much reduced, but remained higher than in lean control subjects, particularly in IGT and type 2 diabetic patients. In contrast, mean plasma glucose concentrations were no longer higher than those of lean control subjects in the NGT, IGT or type 2 diabetes groups.

The impact of surgery on weight loss was strongly time dependent. Thus, in the patients examined 3 months or longer after surgery, weight loss averaged 37\% (range 12 $53 \%$ ). In contrast, the weight loss in patients examined within 10 days of BPD was $6 \%$ at most. In the patient group as a whole, the relative weight loss was strongly and directly related to the time elapsed since surgery $(r=0.83$, $p<0.0001$, both variables $\log$ transformed).

Insulin sensitivity

Before surgery, insulin sensitivity was impaired in all obese patients compared with lean control subjects (Table 2 and Fig. 1). Following surgery, insulin sensitivity increased significantly in each group, reaching levels that were not different from those of the lean control subjects in IGT and type 2 diabetic subjects, and that were even higher than in control subjects in the NGT group. The percentage increase was more pronounced in type 2 diabetic subjects $(\sim 70 \%)$, in whom insulin sensitivity was lowest at baseline. Among the BPD group as a whole, the increase in insulin sensitivity was only weakly related to weight loss $(r=0.39$, $p<0.05$, variables log transformed). In fact, when the follow-up examinations were grouped into those carried out within 10 days $(n=8)$, between 11 days and 18 months $(n=10)$, or longer than 18 months $(n=14)$ after surgery, insulin sensitivity was already within the normal range at the earliest time post-surgery, when weight change was negligible, and was above normal when body weight was still above the normal range (Fig. 2). Decrements in mean post-OGTT plasma glucose levels in the three groups averaged $3.5 \pm 0.5,4.6 \pm 0.8$ and $3.1 \pm 0.6 \mathrm{mmol} / \mathrm{l}$ (all $p<0.0001$ vs zero, i.e. no change).

Non-BPD surgical patients

In the group of subjects undergoing surgery for reasons other than BPD, the weight loss was $1.7 \pm 1.9 \mathrm{~kg}(\sim 1 \%)$. Insulin sensitivity did not change $(373 \pm 80$ vs $368 \pm 80 \mathrm{ml}$ $\min ^{-1} \mathrm{~m}^{-2}$ post-surgery) and the two insulin sensitivity measurements were strongly correlated $(r=0.74, p<0.0001)$. In addition, glucose tolerance category was largely unaltered after surgery: the diabetic subjects remained diabetic (except one, who had a diabetic fasting glucose concentration and was classed as IFG after surgery). On average, surgery slightly worsened glycaemic control: mean postOGTT glucose levels were a little higher after surgery than pre-surgery $(8.8 \pm 3.3$ vs $8.2 \pm 3.1 \mathrm{mmol} / 1, p<0.001)$. In parallel with this $\sim 8 \%$ increase, mean post-OGTT Cpeptide increased slightly (by $\sim 5 \%$, from $924 \pm 24$ to $971 \pm 24 \mathrm{pmol} / 1, p<0.002)$.

Beta cell function

Before surgery, the fasting insulin secretion rate was increased in NGT, IGT and type 2 diabetic patients compared with lean control subjects, whereas beta cell

Table 2 Insulin sensitivity and beta cell function parameters

\begin{tabular}{|c|c|c|c|c|c|c|c|c|}
\hline & \multirow{2}{*}{$\begin{array}{l}\text { Control } \\
\text { subjects }\end{array}$} & \multicolumn{2}{|l|}{ NGT } & \multicolumn{2}{|l|}{ IGT } & \multicolumn{2}{|c|}{ Type 2 diabetes } & \multirow{2}{*}{$\begin{array}{l}\mathrm{BPD}^{\mathrm{a}} \\
\text { effect }\end{array}$} \\
\hline & & Pre-surgery & Post-surgery & Pre-surgery & Post-surgery & Pre-surgery & Post-surgery & \\
\hline 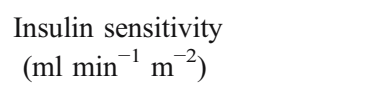 & $478 \pm 49$ & $402 \pm 48^{b}$ & $552 \pm 52^{\mathrm{b}}$ & $324 \pm 100^{\mathrm{b}, \mathrm{c}}$ & $497 \pm 51^{\mathrm{c}}$ & $287 \pm 30^{\mathrm{b}, \mathrm{c}}$ & $477 \pm 41^{\mathrm{c}}$ & + \\
\hline 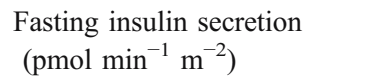 & $67(43)$ & $168(123)^{\mathrm{b}}$ & $65(23)$ & $135(102)^{\mathrm{b}}$ & $57(59)$ & $121(75)^{\mathrm{b}}$ & $76(51)$ & + \\
\hline Insulin output $\left(\mathrm{nmol} / \mathrm{m}^{2}\right)$ & 37 (18) & $53(22)^{b}$ & $26(19)$ & $46(12)^{b}$ & $28(20)$ & $36(13)$ & $20(9)^{\mathrm{b}}$ & + \\
\hline $\begin{array}{l}\text { Glucose sensitivity } \\
\left(\mathrm{pmol} \mathrm{min}^{-1} \mathrm{~m}^{-2} 1 \mathrm{mmol}^{-1}\right)\end{array}$ & $82(98)$ & $78(71)$ & $78(52)$ & $55(34)$ & $95(92)$ & $25(18)^{\mathrm{b}, \mathrm{c}}$ & $30(62)^{\mathrm{b}, \mathrm{c}}$ & \\
\hline $\begin{array}{l}\text { Rate sensitivity } \\
\left(\mathrm{nmol} \mathrm{m}^{-2} 1 \mathrm{mmol}^{-1}\right)\end{array}$ & $0.6(1.0)$ & $0.0(0.7)$ & $0.0(0.3)$ & $0.4(1.1)$ & $1.0(1.1)$ & $0.4(0.8)$ & $0.3(0.5)$ & \\
\hline Potentiation ratio (fold) & $1.3(0.7)$ & $1.2(0.5)$ & $1.5(0.6)$ & $1.3(0.4)$ & $1.1(0.2)$ & $1.1(0.4)$ & $1.0(1.0)$ & \\
\hline
\end{tabular}

Data are means \pm SD or medians (interquartile range)

${ }^{a}$ The plus sign indicates $p \leq 0.05$ for the difference between pre- and post-surgery by two-way ANOVA for repeated measures

${ }^{\mathrm{b}} p \leq 0.05$ vs control subjects by Bonferroni-Dunn test

${ }^{c} p \leq 0.05$ vs the NGT group by Bonferroni-Dunn test 


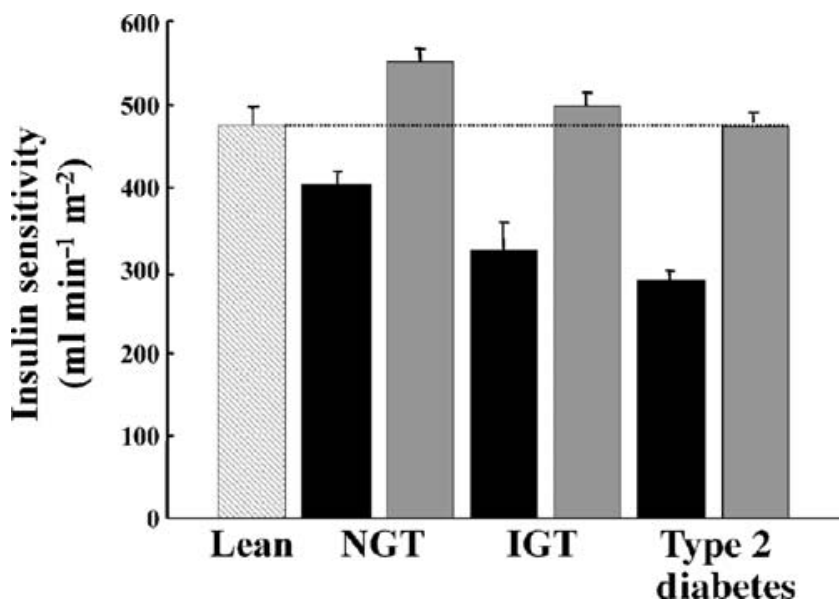

Fig. 1 Insulin sensitivity in severely obese patients before (black bars) and after (gray bars) BPD and in lean control subjects (hatched bar). Bars represent means \pm SEM

glucose sensitivity was decreased in type 2 diabetes (Table 2). Following surgery, the fasting insulin secretion rate and total insulin output decreased. There was a tendency towards an improvement in beta cell glucose sensitivity in IGT and type 2 diabetes, but the change did not reach statistical significance. Furthermore, beta cell glucose sensitivity remained significantly impaired in type 2 diabetic patients compared with lean control subjects. No systematic between-group differences were found in terms of rate sensitivity or potentiation, either before or after surgery.

Surgery was associated with coordinated changes in insulin sensitivity and total insulin output, the latter decreasing as the former increased (Fig. 3). In the BPD group as a whole, glucose tolerance, as determined by the mean glucose level during the test, was inversely related in bivariate regression to both insulin sensitivity (partial

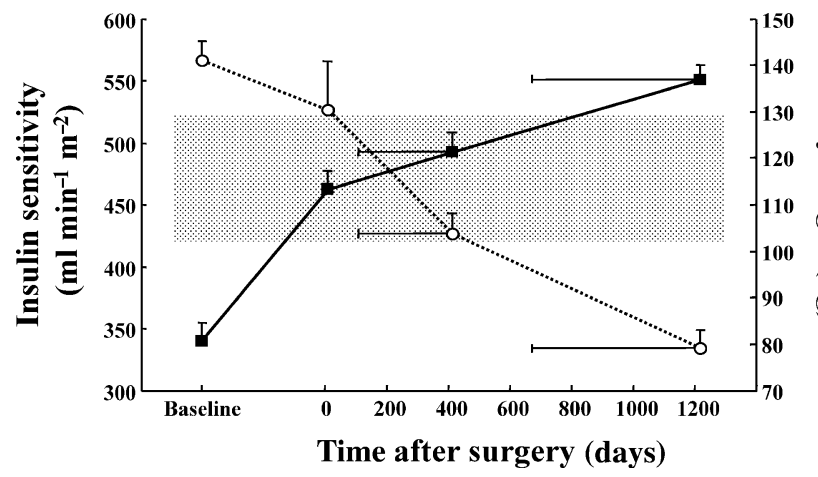

Fig. 2 Time course of changes from baseline in body weight (open circles, broken line) and insulin sensitivity (filled squares, solid line) in severely obese patients at different times after surgery. Symbols plot the median and interquartile range for the $x$-axis and mean \pm SEM for the $y$-axis. The shaded area represents the insulin sensitivity range in lean control subjects (mean $\pm 1 \mathrm{SD})$. The four groups include: baseline $(n=32)$, OGTT within 10 days $(n=8)$, OGTT between 11 days and 18 months $(n=10)$, OGTT more than 18 months $(n=14)$ after surgery

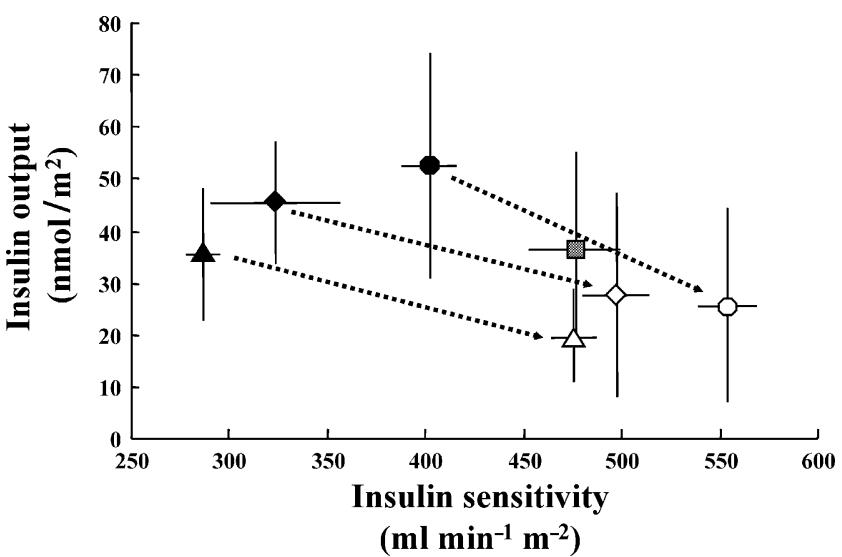

Fig. 3 Changes in insulin sensitivity and total insulin output during the OGTT in severely obese patients (circles, NGT; diamonds, IGT; triangles, type 2 diabetes) before (filled symbols) and after surgery (open symbols) and in lean control subjects (hatched square). Symbols plot the mean \pm SEM for insulin sensitivity and median and interquartile range for insulin output

$r=-0.76, p<0.0001)$ and beta cell glucose sensitivity (partial $r=-0.41, p<0.001$ ), with an explained variance of $67 \%$ (after log transformation of all variables). The 2$\mathrm{h}$ plasma glucose levels were reciprocally related to beta cell glucose sensitivity in a curvilinear fashion, both at baseline $\left(y=580 x^{-1.2}, r=-0.61, p<0.0001\right)$ and after surgery $\left(y=4,113 x^{-2.6}, r=-0.44, p=0.01\right)$, but the two relations were significantly $(p<0.05)$ different from one another (Fig. 4).

NEFA and adipokines

At baseline, fasting NEFA and leptin concentrations were higher in all obese groups compared with the lean control subjects, while adiponectin levels were lower. Following surgery, all three parameters improved significantly to

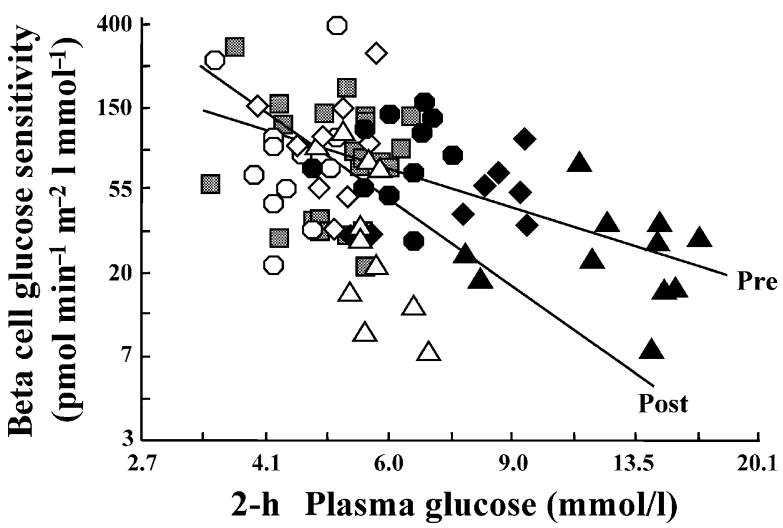

Fig. 4 Relationship between beta cell glucose sensitivity and 2-h plasma glucose concentration in severely obese patients (circles, NGT; diamonds, IGT; triangles, type 2 diabetes) before (filled symbols) and after surgery (open symbols) and in lean controls (hatched squares). The pre- and post-surgery relationships differ significantly from one another $(p<0.05)$ 
Table 3 NEFA and adipocyte hormones

\begin{tabular}{|c|c|c|c|c|c|c|c|c|}
\hline & \multirow{2}{*}{$\begin{array}{l}\text { Control } \\
\text { subjects }^{\mathrm{a}}\end{array}$} & \multicolumn{2}{|l|}{ NGT } & \multicolumn{2}{|l|}{ IGT } & \multicolumn{2}{|c|}{ Type 2 diabetes } & \multirow{2}{*}{$\begin{array}{l}\mathrm{BPD}^{\mathrm{b}} \\
\text { effect }\end{array}$} \\
\hline & & Pre-surgery & Post-surgery & Pre-surgery & Post-surgery & Pre-surgery & Post-surgery & \\
\hline Fasting NEFA $(\mathrm{mmol} / \mathrm{l})$ & $0.23 \pm 0.06$ & $0.41 \pm 0.09^{\mathrm{c}}$ & $0.20 \pm 0.03$ & $0.41 \pm 0.10^{\mathrm{c}}$ & $0.28 \pm 0.13^{\mathrm{d}}$ & $0.53 \pm 0.13^{\mathrm{c}, \mathrm{d}}$ & $0.30 \pm 0.13^{\mathrm{d}}$ & + \\
\hline Leptin $(\mu \mathrm{g} / \mathrm{ml})$ & $12 \pm 2$ & $62 \pm 13^{\mathrm{c}}$ & $18 \pm 14$ & $60 \pm 10^{\mathrm{c}}$ & $34 \pm 20^{\mathrm{c}, \mathrm{d}}$ & $59 \pm 11^{\mathrm{c}}$ & $29 \pm 18$ & + \\
\hline Adiponectin $(\mu \mathrm{g} / \mathrm{ml})$ & $19 \pm 2$ & $9 \pm 2^{c}$ & $20 \pm 4$ & $11 \pm 3^{\mathrm{c}}$ & $15 \pm 6$ & $12 \pm 2^{\mathrm{c}, \mathrm{d}}$ & $16 \pm 5$ & + \\
\hline
\end{tabular}

Data are means $\pm \mathrm{SD}$

${ }^{\text {a }}$ Data were available for five subjects only

${ }^{\mathrm{b}}$ The plus sign indicates $p \leq 0.05$ for the difference between pre-surgery and post-surgery by two-way ANOVA for repeated measures

${ }^{c} p \leq 0.05$ vs control subjects by Bonferroni-Dunn test

d $p \leq 0.05$ vs the NGT group by Bonferroni-Dunn test

levels that were generally no longer significantly different from those of the lean control group (Table 3). Furthermore, in the obese group as a whole, surgery-induced changes in insulin sensitivity were inversely associated with changes in NEFA $(r=-0.67, p<0.0001)$ and leptin $(r=-0.43, p<0.02)$, but not adiponectin. However, in the subjects who were examined within 10 days of surgery, insulin sensitivity was significantly increased, whereas the changes in NEFA and adipokine levels were still minimal.

\section{Discussion}

One important result of this study is that in severely obese patients with IGT or type 2 diabetes, BPD restored NGT and insulin sensitivity. Glucose tolerance and insulin sensitivity were significantly heightened post-surgery, even in patients who were NGT at baseline. Previous studies [4-7] have shown that bariatric surgery is extremely effective in improving glucose tolerance, insulin sensitivity and, to some extent, insulin secretion (as inferred from homeostasis model assessment estimates or the acute insulin response to i.v. glucose). These studies, however, provided a limited description of the simultaneous changes in beta cell function and insulin sensitivity associated with severe obesity and their response to surgical treatment, particularly in the presence of defects in glucose tolerance. Our results show that those obese subjects who are IGT or have type 2 diabetes prior to surgery are characterised by impairment of beta cell glucose sensitivity. This result confirms previous findings that impaired beta cell glucose sensitivity is the main determinant of IGT and type 2 diabetes, rate sensitivity and potentiation being relatively minor factors [17-19]. The impairment in beta cell glucose sensitivity was seen together with a variable degree of insulin resistance and the attendant upregulation of insulin secretion (Fig. 3), as described previously [19]. After surgery, insulin sensitivity and insulin secretion showed reciprocal changes, as shown in Fig. 3.
Our data on beta cell function are not directly comparable with those obtained in previous studies $[5,8,9]$, because of the different surgical techniques (variants of vertical banded gastroplasty) and beta cell function tests (arginine and i.v. glucose infusions). Those studies found a decrease in plasma insulin response and an increase in insulin sensitivity; a disposition index, calculated as the product of the two parameters, was either significantly increased after surgery [5] or unaltered $[8,9]$, suggesting improved or maintained beta cell function. However, the correct assessment of beta cell function changes, through parameters such as the disposition index, requires that beta cell function parameters be independent from glucose levels and clearly related to insulin sensitivity in a control group [20]. In our cohort of control subjects, the parameter that correlated with insulin sensitivity was total insulin output, which is, however, an index that closely depends on glucose levels. Thus, although our post-surgery findings show augmented insulin sensitivity and a reduced insulin secretory response to oral glucose (Fig. 3), precise assessment of the degree of compensation in the groups was not possible.

For similar reasons, the present results on beta cell function cannot be directly compared with those obtained in similar patients using an i.v. glucose test [7]. This study showed that bariatric surgery restored first-phase insulin secretion. In our beta cell model, the parameter that is related to acute insulin response, namely, rate sensitivity, was not significantly affected by treatment (Table 2). This could be due to the insufficient power of the OGTT to detect changes in acute insulin secretion [21], as also indicated by the large variability of the rate sensitivity parameter (Table 2) and its modest reproducibility [16], or to the intrinsic differences between the i.v. glucose test and the OGTT [19].

As expected from previous work [17-19], we found a strong inverse relationship between beta cell glucose sensitivity and glucose tolerance (as the 2-h plasma glucose concentration). This relationship was maintained after surgery, but became significantly steeper (Fig. 4), i.e. the 
same beta cell glucose sensitivity was associated with lower glucose levels after than before surgery. This probably reflects the contribution of improved insulin resistance to glucose tolerance. In fact, beta cell glucose sensitivity and insulin sensitivity together explained almost $70 \%$ of the variability in mean plasma glucose concentrations. Using the regression equation, a subject with the insulin sensitivity of the NGT group but the beta cell glucose sensitivity of the type 2 diabetes group would have a mean glucose level of $7.9 \mathrm{mmol} / \mathrm{l}$, a value in the range of that for IGT subjects $(7.7-10.3 \mathrm{mmol} / \mathrm{l})$. Whether the pattern of glucose absorption, which appears to be complete [22], is a further determinant of glucose levels cannot be established from the results of the present study.

Another novel finding of the present study was that substantial improvements in mean post-OGTT plasma glucose concentrations (averaging $3.5 \mathrm{mmol} / \mathrm{l}$ ) and insulin sensitivity occurred within days of surgery, before any significant weight loss. This early improvement could not be explained by changes in fasting plasma NEFA, leptin or adiponectin concentrations, which were minimal in the first 10 days. This early effect does not appear to be related to non-specific factors associated with surgery, such as acute reduction of nutrient intake. In fact, in the group of patients who underwent abdominal surgery for reasons other than BPD and received the same post-surgery nutrition regimen, insulin sensitivityevaluated using the same technique as employed in the present study-was not different 4-10 days after surgery compared with before surgery, nor was glucose tolerance improved by surgery. The obvious limitation of our experimental design is that patients were not studied sequentially at multiple times following surgery. Nevertheless, a marked improvement in insulin sensitivity was observed in all eight of the patients studied within 10 days of surgery (one with NGT, four with IGT and three with type 2 diabetes).

It can be hypothesised that some unknown regulator of insulin sensitivity is directly affected by BPD. With regard to this, it should be noted that while several surgical techniques leave the duodenum in place, duodenal transit is excluded in the standard BPD. Indeed, exclusion of the duodenum from alimentary transit has been shown to be crucial for the reversion of diabetes in Goto-Kakyzaky rats [23]. Thus, some hitherto unknown substance with insulin desensitising properties would be produced in the duodenal tract of severely obese subjects upon nutrient passage; shunting food downstream to the duodenum would result in a fall in the release of such substance, with a consequent brisk improvement in insulin action.

We did not measure the classical gastrointestinal hormones potentially involved in glucose homeostasis (glucose-dependent insulinotropic peptide, glucagon-like peptide 1, ghrelin, and others), which are known to change after bariatric surgery and have been postulated to play a role in the insulin sensitivity increase (e.g. [24]). However, these hormones do not seem likely candidates, as there is no evidence that they can cause drastic changes in insulin sensitivity such as observed in this study. An effect on beta cell function is, on the other hand, possible.

Several relevant questions remain to be answered. Firstly, it would be important to test whether the severe beta cell glucose insensitivity of severely obese patients with type 2 diabetes eventually recovers up to normal levels. Secondly, it is not clear to what extent the severe obesity model reflects pathophysiological processes occurring in moderately obese or in non-obese subjects with IGT or type 2 diabetes. Finally, the nature and dynamics of putative factors released by the upper gastrointestinal tract must be investigated by appropriate experimental models in animals and clinical designs in humans.

\section{References}

1. Buchwald H, Avidor Y, Braunwald E et al (2004) Bariatric surgery: a systematic review and meta-analysis. JAMA 292:1724-1737

2. Rubino F, Gagner M (2002) Potential of surgery for curing type 2 diabetes mellitus. Ann Surg 236:554-559

3. Rubino F, Gagner M, Marescaux J (2001) Surgical treatment of type 2 diabetes mellitus. Lancet 358:668-669

4. Mingrone G, DeGaetano A, Greco AV et al (1997) Reversibility of insulin resistance in obese diabetic patients: role of plasma lipids. Diabetologia 40:599-605

5. Guldstrand M, Ahren B, Adamson U (2003) Improved beta-cell function after standardized weight reduction in severely obese subjects. Am J Physiol Endocrinol Metab 284:E557-E565

6. Dixon JB, Dixon AF, O'Brien PE (2003) Improvements in insulin sensitivity and beta-cell function (HOMA) with weight loss in the severely obese. Homeostatic model assessment. Diabet Med 20:127-134

7. Polyzogopoulou EV, Kalfarentzos F, Vagenakis AG, Alexandrides TK (2003) Restoration of euglycemia and normal acute insulin response to glucose in obese subjects with type 2 diabetes following bariatric surgery. Diabetes 52:1098-1103

8. Letiexhe MR, Desaive C, Lefebvre PJ, Scheen AJ (2004) Intact cross-talk between insulin secretion and insulin action after postgastroplasty recovery of ideal body weight in severely obese patients. Int J Obes Relat Metab Disord 28:821-823

9. Letiexhe MR, Scheen AJ, Gerard PL, Desaive C, Lefebvre PJ (1995) Postgastroplasty recovery of ideal body weight normalizes glucose and insulin metabolism in obese women. $J$ Clin Endocrinol Metab 80:364-369

10. Pories WJ, Swanson MS, MacDonald KG et al (1995) Who would have thought it? An operation proves to be the most effective therapy for adult-onset diabetes mellitus. Ann Surg 222:339-350

11. Scopinaro N, Gianetta E, Civalleri D, Bonalumi U, Bachi V (1979) Bilio-pancreatic bypass for obesity. II. Initial experience in man. Br J Surg 66:618-620

12. Heymsfield SB, Lichtman S, Baumgartner RN et al (1990) Body composition of humans: comparison of two improved fourcompartment models that differ in expense, technical complexity, and radiation exposure. Am J Clin Nutr 52:52-58

13. DeFronzo RA, Tobin JD, Andres R (1979) Glucose clamp technique: a method for quantifying insulin secretion and resistance. Am J Physiol 273:E214-E223 
14. Mari A, Pacini G, Murphy E, Ludvik B, Nolan JJ (2001) A model-based method for assessing insulin sensitivity from the oral glucose tolerance test. Diabetes Care 24:539-548

15. Mari A, Tura A, Gastaldelli A, Ferrannini E (2002) Assessing insulin secretion by modeling in multiple-meal tests: role of potentiation. Diabetes 51(Suppl 1):S221-S226

16. Mari A, Schmitz O, Gastaldelli A, Oestergaard T, Nyholm B, Ferrannini E (2002) Meal and oral glucose tests for the assessment of $\beta$-cell function: modeling analysis in normal subjects. Am J Physiol Endocrinol Metab 283:E1159-E1166

17. Ferrannini E, Gastaldelli A, Miyazaki Y, Matsuda M, Mari A, Defronzo RA (2005) $\beta$-Cell function in subjects spanning the range from normal glucose tolerance to overt diabetes: a new analysis. J Clin Endocrinol Metab 90:493-500

18. Ferrannini E, Gastaldelli A, Miyazaki Y et al (2003) Predominant role of reduced $\beta$-cell sensitivity to glucose over insulin resistance in impaired glucose tolerance. Diabetologia 46: $1211-1219$
19. Ferrannini E, Mari A (2004) Beta cell function and its relation to insulin action in humans: a critical appraisal. Diabetologia 47:943-956

20. Mari A, Ahren B, Pacini G (2005) Assessment of insulin secretion in relation to insulin resistance. Curr Opin Clin Nutr Metab Care 8:529-533

21. Steil GM, Hwu CM, Janowski R et al (2004) Evaluation of insulin sensitivity and beta-cell function indexes obtained from minimal model analysis of a meal tolerance test. Diabetes 53:1201-1207

22. Tataranni PA, Mingrone G, Greco AV et al (1994) Glucoseinduced thermogenesis in postobese women who have undergone biliopancreatic diversion. Am J Clin Nutr 60:320-326

23. Rubino F, Marescaux J (2004) Effect of duodenal-jejunal exclusion in a non-obese animal model of type 2 diabetes: a new perspective for an old disease. Ann Surg 239:1-11

24. Rubino F, Gagner M, Gentileschi P et al (2004) The early effect of the Roux-en-Y gastric bypass on hormones involved in body weight regulation and glucose metabolism. Ann Surg 240: 236-242 